\title{
Towards a Mobile Application for an Engineering Geology Course A Contribution to Improved Student Learning
}

\author{
João Paulo Barros ${ }^{1,2}$, Pedro Caixinha ${ }^{1}$ and Sofia Soares ${ }^{1,3}$ \\ ${ }^{1}$ ESTIG, Instituto Politécnico de Beja, Beja, Portugal \\ ${ }^{2}$ UNINOVA-CTS, Monte de Caparica, Portugal \\ ${ }^{3}$ Geobiotec, Universidade de Aveiro, Aveiro, Portugal
}

Keywords: Engineering Geology, Ubiquitous Learning, Education, Rock Mass Description, Mobile, Computer Support, Software.

Abstract: One of the subjects studied on engineering geology courses is the description of rock masses and the applica-
tion of geotechnical classifications. Field information is collected and organised in order to make possible to
apply rock mass classification systems and analyse stereographic projection data. The present work proposes
the use of computer supported ubiquitous learning to collect and treat field data. It presents work in progress
towards the creation of a mobile application suitable for Engineering Geology courses. A first prototype for
the Apple iOS system is presented.

\section{INTRODUCTION}

Engineering geology, where students deal with laboratory and field information in order to understand and learn how to classify rocks and rock masses, is a core subject in several higher education study cycles, most notably civil engineering. In fact, "During the feasibility and preliminary design stages of a project, when very little detailed information is available on the rock mass and its stress and hydrologic characteristics, the use of a rock mass classification scheme can be of considerable benefit" (Hoek, 2006).

One of the used learning strategies is to give students a selected rock mass site and ask them to characterise and classify it. Students should be able to collect field data, analyse those data, and make a final report summarising all the information, as well as applying Bieniawski classification system to that rock mass (Bieniawski, 1989).

Based on theoretical lectures and literature, students are exposed to the initial approach, to the classification system, and to needed parameters. Yet, it is during the first field observation that the real problem is presented and effective learning occurs. Each group, composed by three students, has to characterize a section of a rock mass. To that end, they use a template to classify a list of field observations. Study methodology starts with the geographic and geological location of the rock mass, the identification of rock type, texture, colour, weathering degree, discontinuities (faults, folds, schistosity, factures), presence of water, and other relevant factors to the stability of the rock mass.

Recording these data from the rock mass, forces students to use several devices like compass, maps, camera, as well as pencil and paper. Yet, nowadays, with the available technology, it should be possible to collect and record all data in a simpler and more integrated way. Inspired by some related literature (Ho et al., 2012), this paper presents work in progress towards the creation of a computer application for mobile devices, namely tablet computers. The app will allow a simpler and structured way to collect and assemble field information, allowing a more flexible data collection and treatment. Hence, this article presents the motivation for the development of an application to collect field information in order to understand and learn how to classify rocks and rock masses.

The paper is structured as follows: after this introduction, Section 2 presents some background information that contextualises the app functionalities and Section 3 presents the results of a student survey regarding the perceived importance of the tool. After, Section 4 presents the developed prototype and Section 5 concludes. 


\begin{tabular}{|c|c|c|c|c|c|c|c|c|}
\hline \multicolumn{9}{|c|}{ A.CLASSIFICATION PARAMETERS AND THEIR RATINGS } \\
\hline \multicolumn{2}{|r|}{ Parameter } & \multicolumn{4}{|c|}{ Range of values } & & & \\
\hline \multirow{2}{*}{$\begin{array}{l}\text { Strength } \\
\text { of } \\
\text { intact rock } \\
\text { material }\end{array}$} & \multirow{2}{*}{\begin{tabular}{|l|}
$\begin{array}{l}\text { Point-load } \\
\text { strength index }\end{array}$ \\
$\begin{array}{l}\text { Uniaxial comp. } \\
\text { strength }\end{array}$ \\
\end{tabular}} & $>10 \mathrm{MPa}$ & $4-10 \mathrm{MPa}$ & $2-4 \mathrm{MPa}$ & $1.2 \mathrm{MPa}$ & \multicolumn{3}{|c|}{ 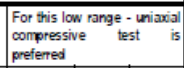 } \\
\hline & & $>250 \mathrm{MPa}$ & $100-250 \mathrm{MPa}$ & $50-100 \mathrm{MPa}$ & $25 \cdot 50 \mathrm{MPa}$ & $\begin{array}{l}5 \cdot 25 \\
\mathrm{MPa} \\
\end{array}$ & $\begin{array}{l}1.5 \\
\mathrm{MPa}\end{array}$ & $\begin{array}{l}<1 \\
\mathrm{MPa}\end{array}$ \\
\hline \multicolumn{2}{|r|}{ Rating } & 15 & 12 & 7 & 4 & 2 & 1 & 0 \\
\hline \multicolumn{2}{|r|}{ Dill core Quality RQD } & $90 \%-100 \%$ & $75 \%-90 \% 6$ & $50 \% \cdot 75 \%$ & $25 \%-50 \%$ & & $<25 \%$ & \\
\hline \multicolumn{2}{|r|}{ Rating } & 20 & 17 & 13 & 8 & & 3 & \\
\hline \multicolumn{2}{|c|}{ Spacing of d s sconifnutites } & $>2 \mathrm{~m}$ & $0.6 \cdot 2 \cdot \mathrm{m}$ & $200-600 \mathrm{~mm}$ & $60-200 \mathrm{~mm}$ & & $<60 \mathrm{~mm}$ & \\
\hline \multicolumn{2}{|r|}{ Rating } & 20 & 15 & 10 & 8 & & 5 & \\
\hline \multicolumn{2}{|c|}{$\begin{array}{l}\text { Conaition of aisconfnuties } \\
\text { (See } \mathrm{E})\end{array}$} & $\begin{array}{l}\text { Very rough surfaces } \\
\text { Not continuous } \\
\text { No separation } \\
\text { Urweathered wall rock }\end{array}$ & $\begin{array}{l}\text { Slighty rough surfaces } \\
\text { Separation }<1 \mathrm{~mm} \\
\text { Slighty weathered walls }\end{array}$ & $\begin{array}{l}\text { Sighty rough sufaces } \\
\text { Separation < } 1 \mathrm{~mm} \\
\text { Highly weathered wals }\end{array}$ & $\begin{array}{l}\text { Slickensided surfaces } \\
\text { or Gouge < } 5 \mathrm{~mm} \text { thick } \\
\text { or Separaton } 1-5 \mathrm{~mm} \\
\text { Continuous } \\
\end{array}$ & $\begin{array}{l}\text { Soft gouge } \\
\text { or Separat } \\
\text { Continuous }\end{array}$ & $\begin{array}{l}\text { e }>5 \mathrm{~mm} \text { thic } \\
\text { tion }>5 \mathrm{~mm} \\
\text { us }\end{array}$ & \\
\hline \multicolumn{2}{|r|}{ Rating } & 30 & 25 & 20 & 10 & \multicolumn{3}{|c|}{0} \\
\hline \multicolumn{2}{|r|}{\begin{tabular}{|l} 
Infow per $10 \mathrm{~m}$ \\
tunnel length $(\mathrm{Um})$
\end{tabular}} & None & $<10$ & $10-25$ & $25-125$ & \multicolumn{3}{|c|}{$>125$} \\
\hline $5 \underbrace{\text { Groundwa }}$ & {$\left[\begin{array}{l}\text { (Joint water pressy) } \\
\text { (Najor principal } \sigma)\end{array}\right.$} & 0 & $<0.1$ & $0.1,-0.2$ & $0.2-0.5$ & & $>0.5$ & \\
\hline & General conditions & Completely diry & Damp & Wet & Dripping & & Flowing & \\
\hline & Rating & 15 & 10 & 7 & 4 & & 0 & \\
\hline B. RATING ADJU & JUSTMENT FOR DISCOI & NUITY ORIENTATIONS (SE & & & & & & \\
\hline Strike and dip orier & orientafons & Very favourable & Favourable & Fair & Unfavourable & & Unfavourab & \\
\hline & Turnels \& mines & 0 & -2 & -5 & -10 & & -12 & \\
\hline Ratings & Foundations & 0 & -2 & -7 & -15 & & -25 & \\
\hline & Slopes & 0 & .5 & -25 & .50 & & & \\
\hline C. ROCK MASS C & SCLASSES DEIERMINE & FROM TOTAL RATINGS & & & & & & \\
\hline Rating & & $100 \leftarrow 81$ & $80 \leftarrow 61$ & $60 \leftarrow 41$ & $40 \leftarrow 21$ & & $<21$ & \\
\hline Class number & & 1 & D & IIII & N & & $\mathrm{v}$ & \\
\hline Description & & Very good rook & Good rook & Fair rock & Poor rock & & ey poor rook & \\
\hline D. MEANING OF & OF ROCK CLASSES & & & & & & & \\
\hline Class number & & 1 & II & IIII & IN & & $\mathrm{v}$ & \\
\hline Average stand-up & top fime & 20 yrs for $15 \mathrm{~m}$ span & 1 year for $10 \mathrm{~m}$ span & 1 week for $5 \mathrm{~m}$ span & $10 \mathrm{hrs}$ for $2.5 \mathrm{~m}$ span & $30 \mathrm{mir}$ & in for $1 \mathrm{~m} \mathrm{sp}$ & \\
\hline Cohesion of rook n & dx mass (kPa) & $>400$ & $300 \cdot 400$ & $200-300$ & $100-200$ & & $<100$ & \\
\hline Friction angle of $n$ & ff rock mass (deg) & $>45$ & $35-45$ & $25 \cdot 35$ & $15-25$ & & $<15$ & \\
\hline E. GUIDELINES F & SFORCLASSIFICATION & F DISCONTINUITY Conditio & & & & & & \\
\hline Discontinuty lengt: & ingth (persistence) & $<1 \mathrm{~m}$ & $1-3 m$ & $3-10 \mathrm{~m}$ & $10 \cdot 20 \mathrm{~m}$ & & $>20 \mathrm{~m}$ & \\
\hline Rating & & 6 & 4 & 2 & 1 & & 0 & \\
\hline Separation (spertu & etture) & None & $<0.1 \mathrm{~mm}$ & $0.1-1.0 \mathrm{~mm}$ & $1.5 \mathrm{~mm}$ & & $>5 \mathrm{~mm}$ & \\
\hline Rating & & 6 & 5 & 4 & 1 & & 0 & \\
\hline Roughiness & & Vey rough & Rough & Slighty rough & Smooth & & Ellickensided & \\
\hline Rating & & 6 & 5 & 3 & 1 & & 0 & \\
\hline |rfilling (gouge) & & None & Hard fliling $<5 \mathrm{~mm}$ & Hard flling > 5 mm & Soff flling $<5 \mathrm{~mm}$ & & filing $>5 \mathrm{~m}$ & \\
\hline & II & 6 & 4 & 2 & 2 & & 0 & \\
\hline $\begin{array}{l}\text { Weathering } \\
\text { Ratinos }\end{array}$ & & $\begin{array}{l}\text { Unweathered } \\
6\end{array}$ & $\begin{array}{l}\text { Slightly weathered } \\
5\end{array}$ & Moserately weathered & Highly weathered & & lecomposed & \\
\hline F. EFFECT OF DI: & DISCONTINUITY STRIK & DIP ORIENTATION IN T & EULING" & & & & & \\
\hline & Strike pen & dicular to thenel axis & & & Fike parale to thanel axis & & & \\
\hline Drive wit & with dip - Dip $45-90^{\circ}$ & Dive with aip & Dip $20-45^{\circ}$ & Dip $45-90^{\circ}$ & 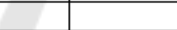 & Dip $20-45^{\circ}$ & & \\
\hline & Very favourable & Favo & & Vey unfavourakle & & Fair & & \\
\hline Drive aga & against dip - Dip $45-90^{\circ}$ & Dive against od & 0 - Dip $2045^{\circ}$ & D & $0-20$ - Irespective of stike ${ }^{\circ}$ & & & \\
\hline & Fair & Untave & mable & & Fair & & & \\
\hline
\end{tabular}

Figure 1: Rock Mass Rating System (after (Bieniawski, 1989)).

\section{BACKGROUND}

Rock mass characterisation is an important part of engineering geology practice. It is relevant that engineers learn how to obtain and read data related to rock mass characterisation.

Even with several limitations, rock mass classifications can be very useful during feasibility and preliminary design stages of a project. Although quite a few classification systems are available, one of the most widespread is the Rock Mass Rating System (RMR), proposed by Bieniawski, originally in 1973 (Bieniawski, 1973).

RMR is obtained through the sum of the different weighing of six parameters (see Figure 1): (1) Uniaxial compressive strength; (2) Rock quality designation; (3) Spacing discontinuities; (4) Condition of discontinuities; (5) Groundwater conditions; (6) Orientation of discontinuities.

The final value obtained will classify the rock mass through five classes, from a very good rock mass (class I) to a very weak rock mass (class V).

Parameters describe the quality of intact rock and the conditions of the discontinuities. Uniaxial compressive strength describes rock resistance. Rock Quality Designation Index (RQD) estimates rock mass quality from drill core logs. RQD is defined as the percentage of intact core pieces longer than 10 


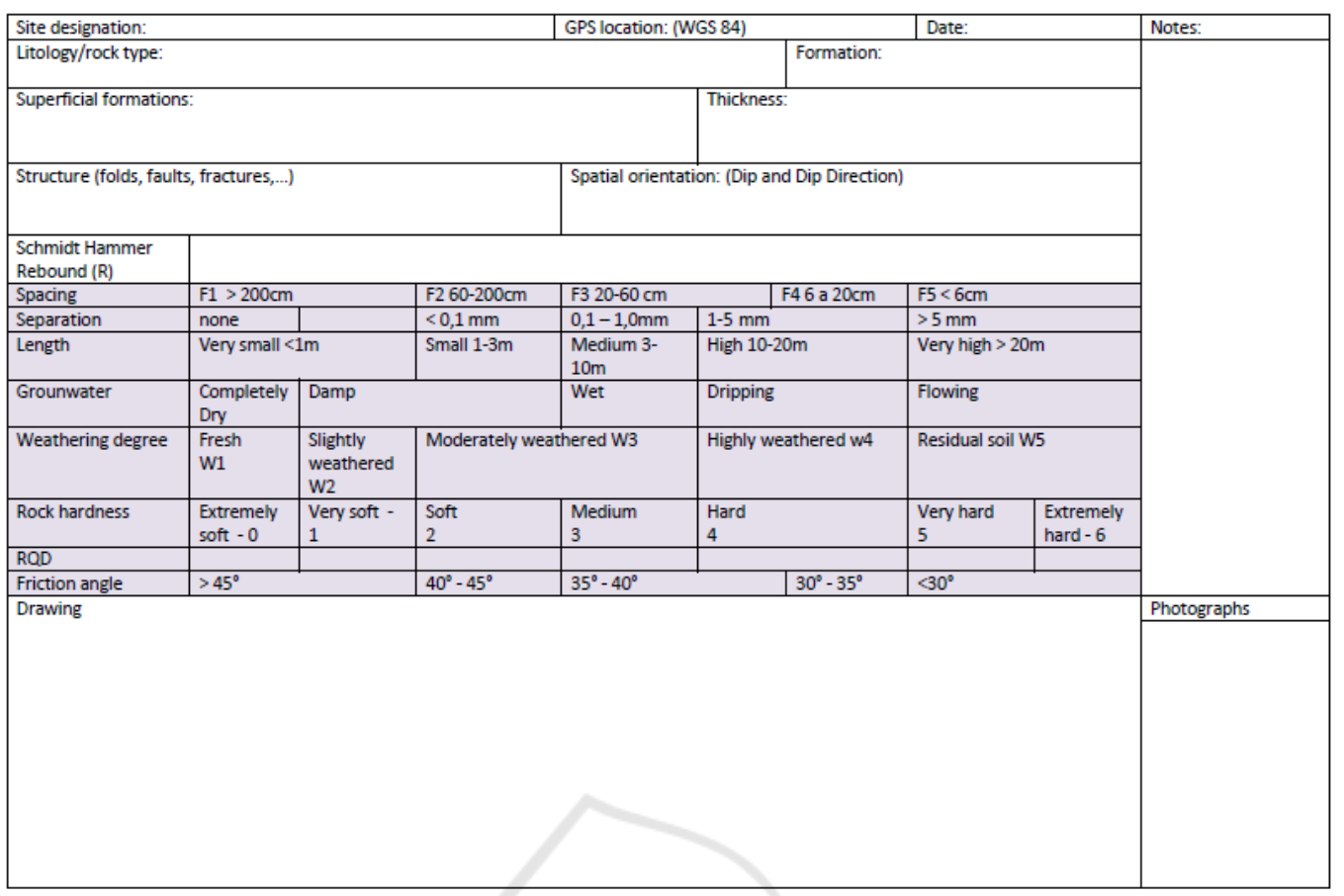

Figure 2: Table to record field data.

$\mathrm{cm}$ in the total length of core drilled. When no core is available, RQD may be estimate, for instance, from the number of discontinuities per unit volume of rock mass (Palmstrøm, 1982). Spacing discontinuities describe the partitioning of the rock mass. Condition of discontinuities defines the importance of weak surfaces. Groundwater conditions show if there can be any water pressure on discontinuities. Orientation of discontinuities can control slope stability.

\subsection{Geological Data Collection and Treatment}

Different classification systems place different emphasis on the various parameters. Hence, at least two classifications should be applied to obtain reasonable results. As our focus is the learning strategies adopted to familiarize students with data recording from the field, from the teacher point of view it is adequate to use only the RMR System.

The first approach is the observation of the rock mass. This is divided into several structural regions so that each group of students works on estimating parameters for a defined region.

Based on RMR system parameters, a table was built to record data from the field (Fig. 2). Students have to identify the site, take its GPS location and categorize it on its geological environment. The use of geological maps, a GPS equipment, or a suitable app in a mobile device is required for determining location. A draw from the rock mass and its environment is convenient and photographs of all relevant aspects should be taken. Hardness of intact rock can be calculated either in situ, using a Schmidt Hammer, or by bringing rock samples to the laboratory and testing them with a uniaxial compression or point load compression equipment. Discontinuities spacing, aperture, and length are measured with a tape measure and values written on the table. Discontinuities spatial orientation (dip and dip direction) are read using a compass with clinometer (Fig. 3). Groundwater, weathering degree, and quick friction angle are determined in the field by local observation and inscribed in the table. Treated data will allow to archive RMR value and classify the rock mass. Values from dip and dip direction of fractures will be placed in stereographic projection (Wulff net) allowing the identification of the main planes of fracturing. The final report will use all field information to recognise eventual geological variability and conclude about rock mass quality.

When preparing future engineers to succeed in solving problems in their professional life, the learning process should also include the use of adequate technologies. Drawing, photographing, GPS locating, accessing digital maps, recording data and using a compass can perfectly be done with a single computer application accessible in a tablet. This solution will help saving time, permit that difficulties emerged on values management to be overcome (bad values or 


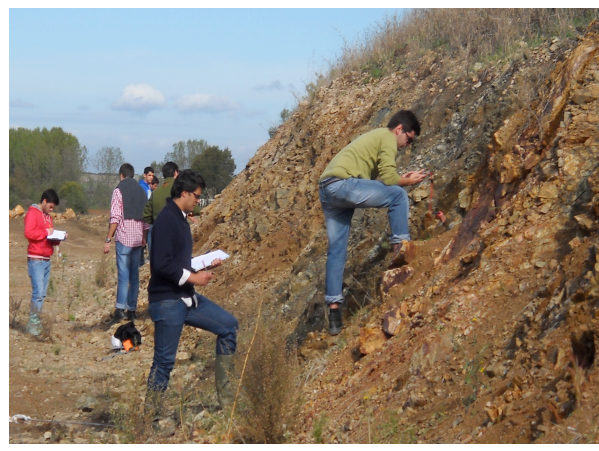

Figure 3: Students collecting field data.

errors due to poor handwriting for instance), and allow an easier data treatment. In the next section, we present the results of a survey applied to a set of geological engineering students.

\section{SURVEY}

To access to students feedback about the use of a computer application for rock mass assignment a questionnaire was applied. Within an universe of 21 students, a total of 15 answers where received, 6 females and 9 males, most with ages between 20 and 25 years. The questionnaire included the following questions:

1. Rate the importance of the following between 1 (not important) and 6 (extremely important):

(a) Importance of a tablet based application for data collection;

(b) Importance of another application for data treatment;

(c) Store all data in digital format;

(d) Use the tablet to take photos, replacing the photo camera;

(e) Use the tablet compass instead of the geological compass;

(f) Use the tablet to draw instead of the paper notebook;

(g) Use the tablet supported maps instead of the paper topographic maps.

2. Specify other relevant data to be included in the application.

The answers to the first two questions show that students find the use of a mobile application for data collection slightly more important than the use of a new application for data treatment (Fig. 4). Usually students use excel spreadsheet to treat data and after a specific software to do stereographic projection.

Regarding specific functionalities, all the five identified functionalities were considered very impor-

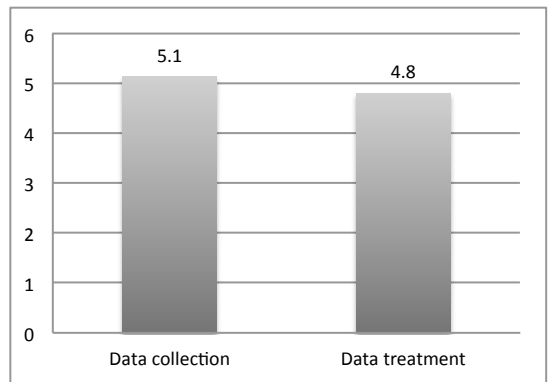

Figure 4: Average importance given to support data collection and data treatment.

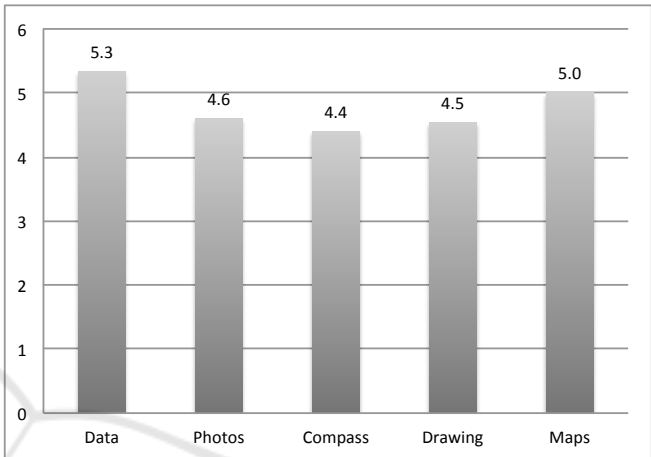

Figure 5: Average importance given to support for several functionalities in the mobile application.

tant, with average values between 4.4 and 5.3 (Fig. 5).

Figure 6 illustrates the minimum, median, and maximum values for the answers to each question. It is interesting to notice that the use of the tablet as a compass and for drawing are the only ones where a respondent gave the lowest score $(1-$ not important).

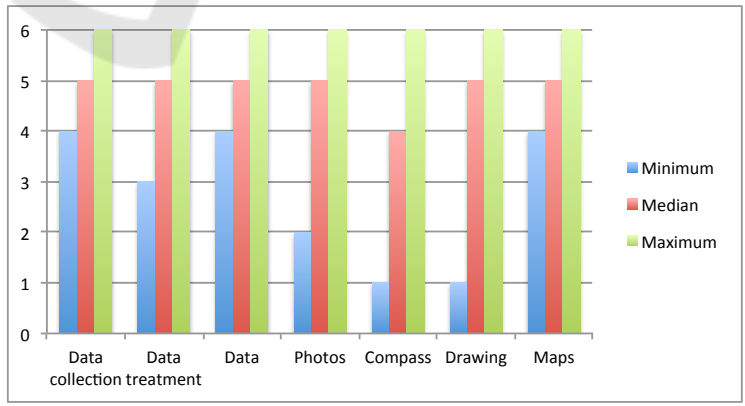

Figure 6: Minimum, median, and maximum values for each question.

Regarding the open question about additional data, the suggestions were the following:

- Support for Excel spreadsheet to register the data related to the taken measures (directions, slopes, and others) allowing they export to other applications (Dips, stereonet or other). 
- The application should automatically generate data to be inserted in an Excel spreadsheet to be latter treated in the laboratory and make a geographical projection with no need for manual editing.

- Insert data in digital format, allowing a faster and more reliable data register

- It would be wonderful to be able to export the retrieved data to pdf, or other, for printing; these data should include meteorological conditions and access to the local.

- Possibility to draw in a vector based format.

- The application could have a table with all the criteria to be assessed on the field for the classification and characterisation of the rock. Besides the field data, it could contain the formulas for data treatment.

It is interesting to see that students find important not only to have an application allowing them to insert all data collected in the field, but also that the applications allow data treatment in other kinds of support. Nevertheless, formulas and data treatment should be done by the users/students as one of the courses learning strategies.

\section{THE APP PROTOTYPE}

Presently, an app for the Apple iOS system is being developed. For this project only field information was considered; the strength of intact rock, one of RMR parameters, was not taken into account because it results from laboratory determination. Based on the data collected in the survey and the teaching experience, the prototype includes support for the following:

- Store all field data in digital format;

- Take photos and record videos;

- Use the tablet compass;

- Use the tablet supported maps;

- Create several "projects" each one with several "sites";

- Creation of a text file (comma separated values) readable in any spreadsheet program or other more specific programs, thus allowing simple and versatile data treatment.

All the data is collected for each site, which belongs to a single project. Hence, the user starts by creating a new project with one site. The data is then collected for this site, including photos. After, the user can add more sites to the project to collect the respective data or a new project with the respective sites.

The app still lacks the possibility to draw and has no formulas for data treatment, which was a student suggestion.

Compared to other existing tools, e.g. (Ho et al., 2012; Terrasolum, 2013; Midland Valley Exploration Ltd, 2013), the tool being developed has two main advantages:

1. It allows for the specification of a specific set of geological data;

2. It offers an integrated support for the registration of all types of data, namely, classifications, measures, photos, and geographic information.

The first functional prototype already developed will allow a preliminary evaluation of its user interface and functionality. Figures 7, 8, 9, and 10 show the more important screens, respectively (1) the project and site screens, (2) the data insertion screen, (3) the clinometer and compass screen, and (4) the photo and video screen.

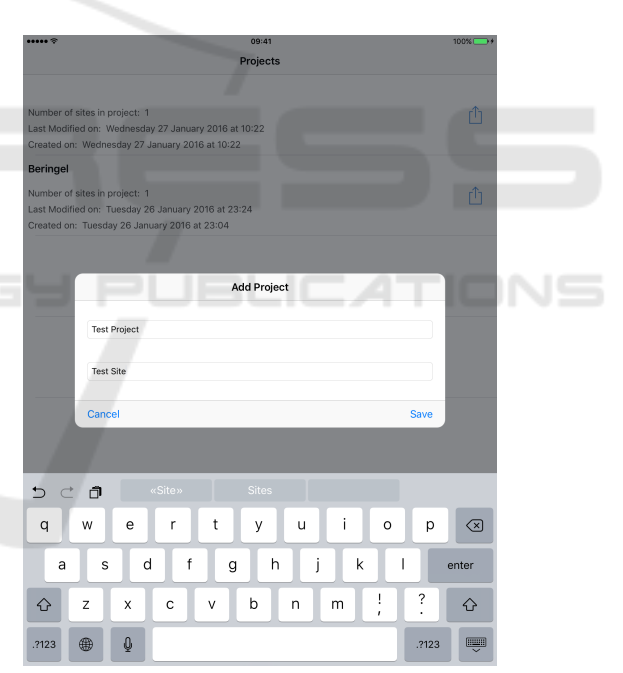

Figure 7: Project screen.

The present tool assumes that the data can be collected for each site in each project. This means that each project can have one or more sites each one with its own data, photos, and videos. Using a tablet compass in a scientific context may be questionable due to its usually bad accuracy. During the project development process various readings were performed with geologist's compass to adjust the application's compass. Preliminary measures seem quite good but future readings should be carried critically in order to ascertain the accuracy. 


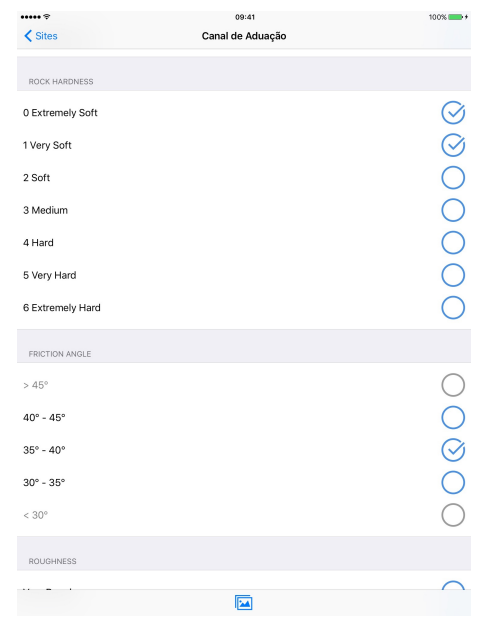

Figure 8: Data insertion screen.

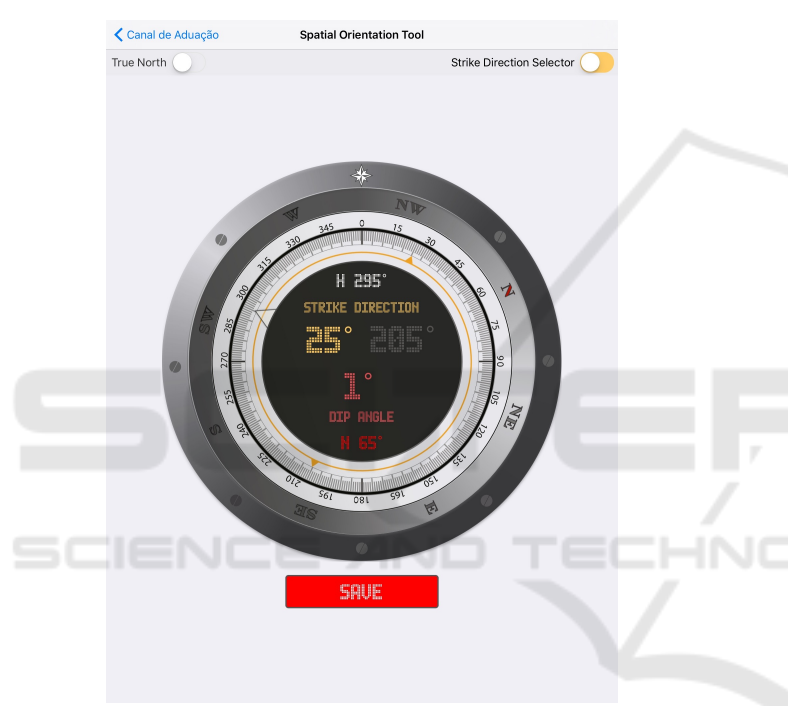

Figure 9: The clinometer and compass screen.

\section{CONCLUSIONS}

It is a natural consequence of the increased sophistication of mobile devices that an increased number of activities will be more efficiently performed ubiquitously based on those devices. Hence, the learning strategies must adapt while taking significant advantage in terms of student efficiency, motivation, and preparation for latter professional activities.

The related existing tools, e.g. (Ho et al., 2012; Terrasolum, 2013; Midland Valley Exploration Ltd, 2013), the survey results, the anecdotal evidence collected along several editions of engineering geology courses taught by the third author, and preliminary testing with a non-functional prototype, have clearly demonstrated that mobile devices and applications will have a pervasive and important role as tools for

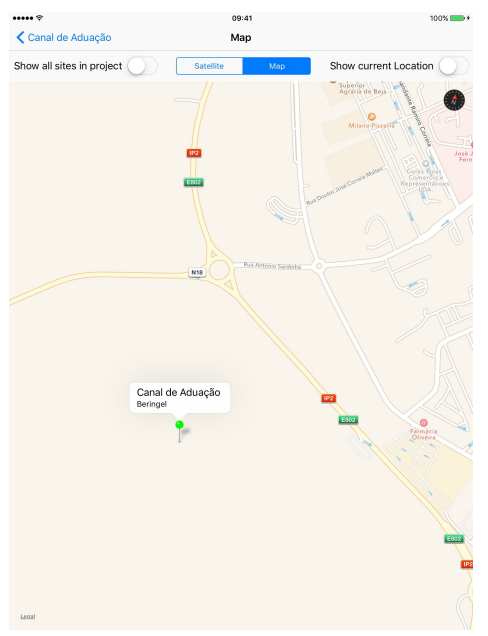

Figure 10: The photo and video screen.

engineering geology students. Although the mobile application is still in a prototype stage the authors are already enthusiastic with the perspective of its use in a very near future.

\section{ACKNOWLEDGEMENTS}

This work is partially supported by National Funds through Portuguese Agency FCT - Fundação para a Ciência e a Tecnologia in the framework of projects PEst-OE/EEI/UI0066/2011 and UID/GEO/04035/2013.

\section{REFERENCES}

Bieniawski, Z. (1973). Engineering classification of jointed rock masses. Transactions of the South African Institution of Civil Engineers, 15(12):335-344.

Bieniawski, Z. (1989). Engineering rock mass classifications. Wiley, New York.

Ho, A., Bekele, K., Malinconico, L., Sunderlin, D., wai Liew, C., Rimal, P., Tillquist, C., and Hoang, K. (2012). GeoFieldBook. The tool is available at the iTunes Store. Accessed on 2014/01/12.

Hoek, E. (2006). Practical Rock Engineering. Available at http://www.rocscience.com/hoek/corner/Practical_Ro ck_Engineering.pdf, accessed on 2014/01/11.

Midland Valley Exploration Ltd (2013). FieldMove Clino. Available at Google Play store. Accessed on 2014/01/12.

Palmstrøm, A. (1982). The volumetric joint count - a useful and simple measure of the degree of rock mass jointing. In Proceedings of the IV Congress International Association of Engineering Geology, New Delhi.

Terrasolum (2013). RMR Calc. Available at Google Play store. Accessed on 2014/01/12. 